\title{
Balzac contemporain, sous la direction de Chantal MASSOL
}

\section{Patrick Berthier}

\section{OpenEdition}

\section{Journals}

Édition électronique

URL : http://journals.openedition.org/studifrancesi/16485

DOI : 10.4000/studifrancesi. 16485

ISSN : 2427-5856

\section{Éditeur}

Rosenberg \& Sellier

\section{Édition imprimée}

Date de publication : 1 juillet 2019

Pagination : 171-172

ISSN : 0039-2944

\section{Référence électronique}

Patrick Berthier, «Balzac contemporain, sous la direction de Chantal mAssoL », Studi Francesi [En ligne], 187 (LXIII | I) | 2019, mis en ligne le 01 juillet 2019, consulté le 25 janvier 2021. URL : http:// journals.openedition.org/studifrancesi/16485; DOI : https://doi.org/10.4000/studifrancesi.16485

Ce document a été généré automatiquement le 25 janvier 2021.

\section{(C) $\odot \Theta$}

Studi Francesi è distribuita con Licenza Creative Commons Attribuzione - Non commerciale - Non opere derivate 4.0 Internazionale. 


\title{
Balzac contemporain, sous la direction de Chantal MASSOL
}

\author{
Patrick Berthier
}

\section{RÉFÉRENCE}

Balzac contemporain, sous la direction de Chantal MASsoL, Paris, Classiques Garnier, 2018, 250 pp.

1 À cause de sa date de publication on pourrait croire que cet intéressant volume, dont l'élaboration collective s'est étendue sur plusieurs années, prend la suite du beau numéro de «L'Année balzacienne» intitulé Balzac, une référence pour le xxe

siècle?

2 Le titre Balzac contemporain est en effet à prendre au pied de la lettre: les onze auteures s'intéressent en exclusivité à des écrivains ou à des cinéastes de la fin du siècle dernier et, majoritairement, à des œuvres postérieures à l'an 2000. La plus ancienne par sa date est un film, le fameux et mythique Out One de Rivette, qui remonte à 1971, et auquel Francesca Dosi revient comme point de départ d'une analyse des deux autres films balzaciens de ce cinéaste, La Belle Noiseuse (1991) et Ne touchez pas la hache (2006). Parmi les écrivains, c'est Jean Rouaud, relu par Hélène BATY-DELALANDE, qui fait assez bien figure de classique reconnu comme tel, avec ses Champs d'honneur de 1990, suivis par toute une œuvre où se manifeste «la pleine incarnation de la puissance des livres» (p. 95; la formule concerne Louis Lambert, mais s'applique bien à Rouaud lui-même). D'autres contributions sont consacrées - et c'est tant mieux - à des auteurs très peu connus en France: Chantal MASSOL, la directrice et préfacière du volume, propose une analyse du roman de W. G. Sebald, Austerlitz (2001), où Chabert le revenant est une image du revenant des camps; ou bien Susi PIETRI traduit elle-même l'entretien qu'elle a eu avec l'écrivain italien Antonio Moresco: même si l'on ignore tout de cet auteur, ce dialogue passionne par la clarté avec laquelle il considère comme désormais dépassée la critique du «réalisme» balzacien par les théoriciens des années 1960. La richesse du 
volume est dans la remarquable diversité des approches, plus encore que dans celle des auteurs retenus: laissons par exemple le lecteur découvrir par quelle analyse subtile et convaincante Véronique BUI en vient à dire, à propos de Dai Sijie, qu'Ursule Mirouët est «le roman le plus chinois de Balzac» (p.178); excellentes aussi, les pages au fil desquelles Catherine DOUSTEYSSIER-KHOZE montre à quel point Chabrol, qui n'a jamais adapté une ligne de Balzac, a une vision balzacienne de la société et de l'âme humaine.

La seule question qui n'est posée nulle part touche des écrivains dont le statut est (aux yeux du signataire de ces lignes, qui les assume) encore incertain au regard de la durée littéraire: qui peut dire qu'on se souviendra dans cinquante ans de Pierre Michon (Joëlle GLEIZE), de François Bon (Anne RoCHE), de Richard Millet (Marion MAS), voire du trop encensé Houellebecq (Christèle couleau)? Je n'écris pas du tout cela contre les auteures de ces articles, tous attentifs et précis; je demande seulement si recueillir des miettes d'interviews sur internet offre un soubassement aussi digne d'intérêt que ce que l'on peut lire en fait de textes critiques achevés et approfondis, stabilisés par le recul du temps - fût-ce d'un temps récent. Question iconoclaste, peut-être, mais faut-il obéir au diktat qui veut qu'on n'étudie plus la littérature qu'à partir de Christian Bobin?

4 Il n'en reste pas moins que l'intérêt porté à Balzac par tous les créateurs évoqués dans ce volume a de quoi interpeller. Aragon ou Gracq, Malraux ou Simenon (exemples choisis dans le volume de «L'Année balzacienne» signalé au début de ce billet) offraient de Balzac des lectures diverses, mais dans toutes Balzac était reconnu; il faut admettre qu'il en va de même de ce Balzac contemporain. Malgré le côté précaire dont j'ai parlé, beaucoup des textes réunis ici confirment ce que la critique balzacienne dit depuis déjà longtemps (les travaux de plusieurs des contributrices sont là pour le prouver), à savoir qu'il faut abandonner une bonne fois pour toutes l'idée d'un Balzac figé; sa richesse est d'offrir à chaque artiste qui le lit selon son prisme et le revendique comme inspirateur un modèle différent, mouvant: que l'un cherche par son entremise à «formuler des lois susceptibles d'éclairer notre perception du réel» (Houellebecq, selon C. Couleau, p. 72) n'est pas contradictoire avec la vision qu'a de Balzac (ou de Proust) un Raúl Ruiz, aux yeux d'Anne-Marie BARON pour qui, on le sait, l'idée d'adapter Balzac (ou un autre) est un non-sens: un art n'en copie pas un autre, un artiste n'en copie pas un autre; mais il est vrai, et c'est presque le mot ultime du volume, que l'écriture de Balzac est «plus fantastique que référentielle» (p. 236), et qu'ainsi elle offre à tous, destinés à durer ou non dans la mémoire des hommes, une réserve inépuisable d'imaginaire. C'est cela qui compte, et pour le reste la postérité fera son tri. 